\title{
Libertad metafísica: los usos del concepto «libertad» en Karl Popper, Friedrich Von Hayek y Milton Friedman
}

\author{
Metaphysical freedom: the uses of the concept \\ «freedom» in Karl Popper, Friedrich Von Hayek and \\ Milton Friedman
}

Facundo Guadagno Balmaceda Universidad Nacional de San Martín facundo.guadagno@gmail.com

\section{Resumen}

En los últimos cuarenta años se produjo una neoliberalización de los mercados que afectó a la cotidianidad de nuestras vidas. Esto no fue un proceso espontáneo, más bien, tuvo sus ideólogos más o menos precisos, con menor o mayor influencia: Karl Popper, Friedrich Von Hayek y Milton Friedman. 
Una de las categorías que se suele utilizar en esta etapa del capitalismo es la de «libertad»: precisamente, este artículo pretende explorar los usos que estos autores hacen de este concepto.

Palabras clave: neoliberalismo, historia cultural, liberalismo, globalización

\section{Abstract}

In the last forty years there has been a neoliberalization of the markets that affected our daily lives. This was not a spontaneous process, rather, it had its more or less precise ideologues, with less or more influence: Karl Popper, Friedrich Von Hayek and Milton Friedman. One of the categories that is usually used in this stage of capitalism is "freedom»: precisely, this article aims to explore the uses that these authors make of this concept.

Key words: neoliberalism, cultural history, liberalism, globalization.

\section{Introducción}

A partir de los últimos cuarenta y cincuenta años se produjo la llamada «neoliberalización de los mercados», concepto que suele homologarse al de globalización, aunque es más preciso operacionalizarlo y señalar que las finanzas, la tecnología, la investigación y el desarrollo, junto 
a la flexibilización laboral, han marcado la agenda de la economía mundiall ${ }^{1}$. Esto no surgió espontáneamente, más bien, es parte de procesos políticos, pero también de intercambios de ideas que culminaron siendo adoptadas, con mayor o menores matices, por todos los gobiernos, conformando lo que algunos académicos denominaron «la hegemonía neoliberal» (Plehwe, 2007). Esta etapa del capitalismo enfatiza el rol del individuo, premiando a la productividad y la creatividad, sin requerir horarios ni salarios fijos (Castel, 2010), entre otras características.

Nada de esto fue azaroso, más bien, se pensó mucho antes de que se implementara; de hecho, fue ampliamente considerado por tres influyentes intelectuales: Karl Popper,

1 De cualquier manera, es necesaria una definición mínima de globalización para saber a qué nos estamos refiriendo cuando utilizamos el concepto, en consecuencia, creo conveniente recuperar la delimitación que hacen Alonso y Conde (1996) que, si bien es extensa, la resume en sus términos generales:

El marco económico en el que actualmente nos movemos es un espacio mercantil/global, un espacio en el que el horizonte no es ya tanto un capitalismo industrial y material, como un capitalismo financiero, virtual e inmaterial $y$ en el que los espacios comerciales se juegan ya no como un intercambio de mercancías a nivel internacional, sino como un sistema articulado de empresas-red a nivel transnacional, donde lo que opera ya no es, por tanto, un comercio entre países, entre economías nacionales, como una situación integrada de flujos de información [...]. A la vez que un nuevo sistema de ordenación y complementación de la división internacional del trabajo se establece como un todo orgánico e interdependiente, cruzando las barreras jurídicas de las naciones (1996: 94). 
Friedrich Von Hayek y Milton Friedman, a partir de sus definiciones de libertad y la importancia político-económica que le atribuían, en el proceso histórico que conjugó al New Deal (1933-1983), el surgimiento del Estado de Bienestar, y la Guerra Fría (1945-1991).

Sucede que más allá de sus aportes en epistemología, o específicamente en las disciplinas a las que profesionalmente se dedicaron, estos tres autores abordaron ampliamente el concepto de libertad en su obra $y$, precisamente, examinar sus usos en los trabajos de estos intelectuales es el objetivo de esta investigación, la cual, por otra parte, contemplará los distintos contextos históricos en los que escribieron.

Si bien el material de estudio consiste en el análisis de primera mano sobre las obras de estos autores, fue necesario contemplar al estado del arte sobre cómo estos tres intelectuales abordan el concepto de libertad.

\section{Karl Popper: la libertad como hecho científico}

Las ideas de Karl Popper no fueron escritas en el vacío, sino que dos de sus libros con más impacto intelectual y político, La miseria del historicismo (2002) y La sociedad abierta y sus enemigos (2006), a los que volveremos luego, tuvieron relación directa con el contexto de Guerra Fría, donde no solo se libró una batalla, sintéticamente, entre el liberalismo y los llamados socialismos reales, sino que 
dentro de las democracias liberales existió un fuerte debate respecto al rol del Estado en la sociedad y, en consecuencia, si la mayor intervención de éste tendría un futuro totalitario (Petersen, 2013). A partir de los 70, comienza a producirse una oscilación en las democracias occidentales hacia un liberalismo de libre empresa, contrario al Estado de Bienestar (Hacohen y Milford, 2002), un síntoma de que las ideas del liberalismo filosófico habían triunfado.

Cabe precisar los argumentos utilizados por Karl Popper para poder establecer qué significa la libertad según el pensador austríaco, un concepto que se relaciona con lo que él define como sociedad abierta y su aproximación epistemológica desde el racionalismo crítico. La operacionalización del concepto se desprende de tres argumentos centrales para su pensamiento, a saber: (i) el falsabilismo, (ii) su crítica al historicismo y (iii) su concepción de una sociedad abierta.

Al aproximarnos a (i) nos concentramos en una de las mayores obras de Popper, y también de la epistemología, $L a$ lógica de la investigación científica (2004), en la que se discute con los abordajes inductivistas, como el de Bacon, en pos de identificar cómo se produce el conocimiento, y las maneras más eficientes de eliminar el error (Caro, 2007). Las fuentes de conocimiento deben estar sujetas a refutación científica. Algunas de las definiciones claves de Popper (2004) son explicadas en el trabajo mencionado de Cristian Ortega Caro: 
Las definiciones conceptuales —señala Poppernunca suministran conocimiento fáctico acerca de las cosas, los hechos o sobre la naturaleza de éstos [...]. Los conceptos y su significación son unidades discursivas, cuyo origen de contenido $-\mathrm{y}$ validez cognoscitiva se asienta en la fuente autorizada, en la escuela o la tradición; fuentes que en la perspectiva de Popper no aportan ni a su metodología ni al desarrollo de las ciencias- (Caro, 2007: 21).

No resulta errado concebir que, bajo la perspectiva de Popper, los conceptos tendrían un valor metafísico, mientras que todo lo contrario ocurriría con los sistemas de enunciados, los cuales se rigen por verificación empírica. En términos del concepto de verdad, el filósofo austríaco utiliza el método hipotético-deductivo, es decir, la posibilidad de formular una hipótesis, o conjetura, cuyo valor de verdad se desprende de la posibilidad de ser refutada (Popper, 2004: 30). Esto constituye el criterio de demarcación, para Popper, de qué es ciencia y qué pseudociencia: los postulados deben poder ser contrastados empíricamente, de lo contrario, se alejan del ámbito científico.

Si bien esto parece responder a meras contingencias epistemológicas, el autor es explícito respecto a que tal manera de concebir al mundo, es decir, bajo conjeturas y refutaciones, se opone a lo que él denomina como «esencialismo», es decir, la noción de que distintas teorías son capaces de proveer explicaciones últimas, donde no sea 
necesaria, precisamente, ninguna explicación ulterior (2004: 402). En rigor, la discusión para el filósofo austríaco se dirime contra el marxismo y el psicoanálisis, dos teorías que ingresan dentro de su categoría «esencialista». En consecuencia, la sociedad sólo puede avanzar adoptando el tipo de aproximación que Karl Popper sugiere ya que está sujeto a refutaciones, huyendo de verdades dadas, como las del marxismo, que conducirían al totalitarismo. En este marco, Popper sugiere que la creación científica, fundamental para que una sociedad se desarrolle, sólo puede darse en un contexto de libertad, y si el sistema no lo permite, entonces esta no puede producirse (2004: 260).

Respecto a La miseria del historicismo (2002) y La sociedad abierta y sus enemigos (2006), las dos obras están relacionadas, ya que sus argumentos permiten explicar, bajo el pensamiento político de Popper, las condiciones para la libertad del individuo: ninguna teoría científica puede poseer la cualidad determinista sobre el fenómeno que pretende explicar (Caro, 2007: 28). Bajo estos argumentos, el determinismo metafísico sólo resulta operativo si puede ser refutado (Arana, 2001), lo que deriva en una ontología indeterminista. Precisamente, en Popper (2002) se argumenta que el proceso de avance científico puede darse en contextos en los que el investigador sea libre de publicar, disentir, debatir con colegas y poder ser interrogado sobre los resultados que produce; lo contrario ocurriría si se adoptara al historicismo para concebir a la actividad social, 
ya que las producciones intelectuales estarían marcadas por una fuerte predicción a partir de distintas teorías.

La refutación del historicismo por parte de Popper se basa en los siguientes postulados:

«El curso de la historia está fuertemente influido por el crecimiento de los conocimientos humanos».

«No se puede predecir, de una forma científica, el crecimiento futuro de los conocimientos científicos».

Como consecuencia, no puede predecirse el curso futuro de la historia humana. Lo anterior significa que hay que rechazar la posibilidad de una historia teórica o historia generalizadora ya que se serviría de leyes universales, o hipótesis, que en el caso de la historia no existen. Como conclusión enuncia que «La meta fundamental de los métodos historicistas está, por lo tanto, mal concebida; y el historicismo cae por su base» (Lagoa, 2002: 118).

En rigor, no resulta demasiado difícil discernir qué significa libertad para Popper, pero sí es más complejo establecer las condiciones por las que esta sería posible bajo las premisas del intelectual austríaco. Siguiendo a Popper (2002), Caro sostiene que, para el epistemólogo, libertad refiere a: «la capacidad humana de crear e inventar, esto es, el uso de la imaginación al servicio de la ciencia, en tanto pilar fundamental para la generación constante de 
nuevas y más completas teorías» (Caro, 2007: 28). En este sentido, hay una coincidencia con el señalamiento que hicimos sobre los postulados de Popper (2004) y la libre discusión dentro de la ciencia. Una vez que esto es establecido, se sostiene que ninguna teoría científica, siguiendo su argumento contra el historicismo, puede determinar, a priori, los hechos futuros, inclusive algún grado de predictibilidad teórica (Popper, 2002). Se descarta, así, la regularidad en el acontecimiento futuro de los hechos. En consecuencia, los científicos poseen la libertad de conjeturar, revisar sus hipótesis $y$, bajo un sistema político que lo permita, investigar y someterse a la crítica de sus pares. De esta manera, la libertad política se relaciona con la libertad de creación.

Sin embargo, es preciso puntualizar la discusión que establece Popper en La miseria del historicismo, ya que su texto se caracteriza en buena parte por eludir nombres, y dialogar con historicistas ${ }^{2}$, generalmente en conversaciones imaginadas donde se recuperan argumentos generales del historicismo, pero que luego derivan, específicamente, en una discusión con Platón y Marx, ya que, para él, las teorías de estos dos pensadores se sintetizan en la siguiente afirmación: «la ciencia social no es nada más que historia; esta es la tesis [...]. Es el estudio de las fuerzas que operan

2 En ese sentido, se pueden mencionar sus constantes estrategias argumentativas donde se suele argumentar «comentaría el historicista, diría el historicista», entre variantes similares. 
sobre el desarrollo social y, sobre todo, el estudio de las leyes de éste» (2002: 59).

En ningún momento el autor reniega de la historia, más bien, argumenta que el conocimiento histórico es necesario, pero no es una condición para establecer leyes que permitan predecir comportamientos futuros $y$, en este sentido, bajo un contexto de Guerra Fría, la discusión con el marxismo cobra sentido, ya que Popper la interpreta como una doctrina que permitiría establecer las bases científicas para una nueva sociedad, en los llamados socialismos reales. Este sería un camino al totalitarismo $y$, de aquí, se desprenden ciertas conexiones con Friedrich Von Hayek.

Las relaciones con el intelectual austríaco, por momentos, no son tan específicas, pero al examinar algunas notas al pie, pueden notarse apoyaturas teóricas en Hayek para criticar a los socialismos reales; se pueden enumerar algunos ejemplos, como la imposibilidad de cálculo económico en una economía planificada (2002: 105), las consecuencias negativas de utilizar a la historia como herramienta de predictibilidad (121), la intención de encontrar leyes naturales en el ámbito histórico, cuando la sociedad se organizaría espontáneamente (125), considerar a la sociedad como un organismo (128), entre otros. La conexión con el pensador austríaco es más explícita en un apartado, titulado Nota histórica, en el que Popper sugiere que sus ideas eran similares a las que había expresado en algunos ensayos Friedrich Von Hayek (9). 
Los argumentos de Karl Popper se caracterizan por su solidez en la crítica inmanente a los sistemas filosóficos que él considera nocivos para el desarrollo de una sociedad, considerando, a priori, que la democracia y la libre empresa serían las características a tomar en cuenta para que tal progreso se lleve a cabo. La sociedad abierta y sus enemigos fue escrita durante el exilio de Karl Popper en Nueva Zelanda cuando transcurría la Segunda Guerra Mundial. La caída del socialismo austríaco y el colapso de las democracias en Europa Central fueron algunos de los móviles para este libro, que se convertiría, posteriormente, en un sostén teórico del liberalismo durante la Guerra Fría (Hacohen, 1998). Su anticomunismo convergía con ideas cosmopolitas donde, por ejemplo, se eliminaran problemas de discriminación étnica y la prevalencia del Estado-Nación cesara (Hacohen, 1999). La obra busca rastrear las raíces del totalitarismo moderno, que Popper encuentra en Platón, Hegel y Marx, culpables directos, para el autor, de la Segunda Guerra Mundial, con especial impacto el año 1943, fecha en la que fue escrito el libro. Platón sería quien reemplazó a la democracia por el autoritarismo en Atenas, mientras que Hegel construyó su filosofía para servir al nacionalismo del Estado prusiano. Por último, Marx, en esencia un demócrata progresista, devenía, indefectiblemente, en un pensador autoritario considerando su doctrina de inevitabilidad histórica de la revolución socialista (Hacohen, 1998: 730). 
Las reflexiones presentadas en Miseria del historicismo y La sociedad abierta y sus enemigos convirtieron a Popper, a partir de la posguerra, en un conservador, que se alió con el austríaco Friedrich Von Hayek (Hacohen). Karl Popper es explícito sobre lo que significa una sociedad abierta, la cual es una sociedad que:

rechace la autoridad absoluta de lo establecido por la mera fuerza del hábito y de la tradición, tratando, por el contrario, de preservar, desarrollar y establecer aquellas tradiciones, viejas o nuevas, que sean compatibles con las normas de la libertad, del sentimiento de humanidad y de la crítica racional (2004: 12).

No obstante, esta definición utiliza al vago concepto de libertad, que tampoco se define, pero puede inferirse como oposición a la coerción externa, que generalmente Popper vincula con lo propuesto por Platón, Hegel y Marx, y las pocas garantías para el desarrollo individual al concebir las doctrinas de estos tres pensadores.

Se pueden contar varios problemas en los argumentos de Popper. Si la libertad de creación científica, considerada fundamental para el desarrollo en la visión del filósofo, se realiza con libertad política: ¿bajo qué sistemas puede verse esto operacionalizado más allá del ideal metafísico planteado por Popper? Es decir, en un primer período, este estado ideal puede ocurrir, pero, ¿qué nos garantiza que 
continúe ocurriendo a lo largo del tiempo? ¿Qué cualidades deben poseer estas instituciones y cómo podemos observarlo empíricamente? Como se evidencia, no hay azar, ni creatividad, baluartes de la sociedad abierta en Popper, que sirvan para satisfacer estos argumentos, sino, por el contrario, la necesidad de hechos que contrasten las proposiciones.

\section{Friedrich Von Hayek: la filosofía de la libertad}

El Premio Nobel de Economía, Friedrich Von Hayek, quizá sea más reconocido por sus aportes a la filosofía política que, precisamente, a las ciencias económicas, en las que se destacan sus trabajos sobre la teoría del ciclo económico y la importancia de la información en la economía ${ }^{3}$. Sin embargo, una de sus obras más exhaustivas, Los fundamentos de la libertad (1998), es una disección del concepto de libertad, su naturaleza, la relación que guarda con la ley, y, por último, un análisis sobre el Estado de Bienestar.

Para Hayek la libertad, sintéticamente, implica la ausencia de coerción, cuestión que lo coloca en la tradición del liberalismo escocés (Sufrin, 1961), e incluso, con las bases del pensamiento hobbesiano (Skinner, 2012). No

3 Sobre estos tópicos, ver: Gómez Betancourt (2008), Jürgensen y Rosende (1993), Von Hayek (1937). 
obstante, algunas precisiones sobre el concepto le quitan a Hayek una relación tan estrecha con lo que él denomina la «definición pura» de libertad (1998: 41) —ausencia de coerción-, ya que considera ciertas ocasiones en las que no existe libertad de elección por el mero hecho de que tal posibilidad no existe, es decir, no es una de las opciones reales que el individuo puede tomar o siquiera considerarlas como posibles.

En Los fundamentos de la libertad, sin embargo, es bastante restrictivo sobre a qué se refiere con libertad: «esta obra hace referencia a aquella condición de los hombres en cuya virtud la coacción que algunos ejercen sobre los demás queda reducida [...] al mínimo» (Hayek, 1998: 40). Desde ya, esto implica un grado considerable de abstracción para la lógica del intelectual austríaco, más allá de que incluya la aceptación de alguna coerción para el bien común, es decir, el gobierno de la ley. El Ilamado rule of law aparece en el núcleo del pensamiento de Hayek, ya que aquí no se habla de hombres particulares, sino de instituciones impersonales, las cuales fueron creadas naturalmente (Hayek, 1946).

La definición de libertad en Hayek (1998) se refiere sustancialmente a la ausencia de coerción de otro u otros; esto no es fácil de llevar a cabo, sin embargo, es la meta a la que se debería aspirar como sociedad. La noción «pura» de libertad contrasta con la libertad política, que referiría a la independencia de un pueblo de la coerción interna -el gobierno de un déspota, por ejemplo- y externa -el ataque de otra comunidad-. La «libertad interior», por otra 
parte, se remite al control de las emociones y los actos irracionales. Una última definición sería la «libertad como poder», la cual se refiere a la potestad de llevar a cabo una acción: para el autor, esto podría llevar al totalitarismo, ya que sería un poder sin control alguno. El ejemplo que utiliza el intelectual austríaco es el de los socialismos reales (1998: 52-53).

Todo esto puede comprenderse bajo el contexto de lo que, dentro del pensamiento de Friedrich Von Hayek denota «lo natural» $y$ «lo artificial»: La palabra «natural» se refiere a lo que él denominó "cataláctica», es decir, la organización espontánea de los individuos a partir de las señales de precios del mercado (Hayek, 1982). De esta manera, los agentes económicos sabrían a la perfección qué es lo deben realizar para que la sociedad se reproduzca. Ante esto no se supone que sean racionales, sino que, simplemente, en la creatividad del mercado el orden social podría perdurar, siempre y cuando exista una ley superior, una Constitución, que regule este orden. Como se mencionó, esta es la única coerción que Hayek acepta.

Sin embargo, existen otras coerciones que Hayek también considera válidas, como las que surgen al negociar un contrato de trabajo $y$, como consecuencia, el trabajador deba aprender un oficio (Sufrin, 1961). Se vuelve a observar que los individuos en un mercado libre garantizan, para el autor, la reproducción social. La interferencia de un político sería una institución artificial, algo diseñado que se opone a la creación natural de los individuos, y sólo entorpecería el 
desarrollo de la cataláctica. Una aproximación similar se ve, unos años después, en la escuela de la public choice, liderada por James Buchanan, en la que los políticos son vistos como agentes maximizadores de ganancias (Buchanan, 2003) ${ }^{4}$.

Camino de servidumbre (2007) es particularmente importante en la bibliografía de Hayek debido a la coyuntura: la Segunda Guerra Mundial, durante la que Estados Unidos e Inglaterra abogaban por el liberalismo contra los que Hayek denomina como colectivistas, el fascismo, nazismo y comunismo ${ }^{5}$. No es casualidad que el autor lo catalogara como un libro de índole política (Rosenof, 1974). Su argumento principal yacía en que programas como el New Deal llevarían al totalitarismo, ya que la economía centralmente planificada, en cualquiera de sus matices, interfiere con el proceso de la cataláctica. El libro no separa la libertad política de la económica y, nuevamente, la explotación capitalista, la maximización de la ganancia, es vista como un acuerdo entre partes. El trabajo no considera, siquiera, la obligación de alquilar la fuerza de

${ }^{4}$ Robert Higgs, comentando La fatal arrogancia (2010) señaló que Hayek no mencionaba a ningún autor de la escuela de public choice (Boettke, 1995), sin embargo, más allá de si esta afirmación es verdadera o falsa, ya observamos cómo en Los fundamentos de la libertad, libro originalmente editado en 1960, se llegaba a conclusiones similares a las que luego expondrían en las teorías de la elección pública.

${ }_{5}^{5}$ Para el análisis de las ideas político-económicas, no es relevante el papel que haya jugado la Unión Soviética para el bando aliado. 
trabajo para subsistir, en consecuencia, la libertad como ausencia de coerción, que se presume estatal, carece de sentido y peca de ingenuidad sobre el sector privado. La importancia de esta obra yace en su carácter político, ya que su idealismo hace que sus hipótesis sean difíciles, o imposibles, de contrastar.

El impacto político de Camino de servidumbre llevó a reduccionismos absurdos. Henry Hazlitt y Chamberlain ubicaron a Hayek en la tradición de Locke, Stuart Mill y Lord Acton, por un lado, oponiéndose a Hitler, Mussolini y Marx, por el otro (Rosenof, 1974: 151). Ni Estados Unidos e Inglaterra, como tampoco ningún país durante el apogeo del Estado de Bienestar, se convirtieron en regímenes totalitarios, sólo que para Hayek estarían en camino de serlo.

Camino de servidumbre se editó originalmente en 1944, cuando la Segunda Guerra Mundial aún se estaba desarrollando, y la intención original de Hayek fue la de generar un impacto en intelectuales de izquierda ${ }^{6}$ para que desistan en su interés por apoyar un modelo económico socialista; si bien esto lo logró en un grupo pequeño ${ }^{7}$, el impacto fue en el Partido Conservador, incluso en Churchill,

${ }^{6}$ De allí se desprende su dedicatoria: «a los socialistas de todos los partidos».

7 Entre ellos se cuentan Evan Durbin, Herman Finer, George Orwell y Barbara Wooton. 
quien afirmó que una economía planificada sólo funcionaría con un Estado operando como la Gestapo (Shearmur, 2006).

Otra de las obras emblemáticas de Hayek es La fatal arrogancia (2010), que para su fecha de edición se consideró desactualizada en términos de historia económica, donde ni siquiera se tomaban en cuenta fallas de mercado (Boettke, 1995). Aquí se continúa negando cualquier existencia de procesos sociales en los que el Estado sea un agente económico, incluso la existencia de la sociedad como hecho externo al individuo -algo básico para la sociología - como lo ilustra el siguiente párrafo:

Aun cuando sea tan equívoco el sustantivo «sociedad», mucho más lo es el adjetivo «social», que probablemente se ha convertido en la principal fuente de confusión de nuestro vocabulario moral y político [...]. La confusión creada en los ámbitos en que más se usa dicho término es en cierta medida consecuencia del intento de describir mediante él no sólo determinados fenómenos consustanciales a diversas formas de colaboración interpersonal, tales como las que se dan en una "sociedad», sino también ciertas modalidades de colaboración que promueven la aparición y preservación de tal tipo de órdenes (Hayek, 1997: 335, en Cordero, 2007).

Tal afirmación no contiene ningún rigor científico, pero sí cobra sentido político, en el sentido de negar cualquier 
beneficio del Estado de Bienestar. Sin embargo, Hayek es honesto al afirmar que, a fin de cuentas, su proyecto de libertad individual se lograría mediante una serie de «normas abstractas» que el gobierno protegería (Cordero, 2007: 77). Para el intelectual austríaco no existiría perjuicio alguno en la libertad de mercado, nadie se beneficiaría a costa de nadie, y la coerción estatal impediría «el correcto funcionamiento del orden» (Hayek, 1997: 296, en Cordero, 2007).

La fatal arrogancia sería una suerte de síntesis del pensamiento político de Friedrich Von Hayek. Siguiendo los lineamientos de su obra, el autor afirma que el comercio es garante de la libertad humana, y que esto es así desde los pueblos primitivos, aunque de esto sólo desarrolle una explicación especulativa (2007: 79). Las distintas argumentaciones de Hayek sobre la política, prácticamente sobre la filosofía y epistemología de la misma, están cargadas de erudición, lo cual no las relaciona, necesariamente, con verificaciones empíricas. «El hombre se ha convertido en todo lo que es sin entender qué sucedió», argumenta el pensador austríaco, citando a Vico (Hayek, 1981: 63), con el objetivo de argumentar que los filósofos sociales del siglo XVIII fueron más precisos en señalar el orden espontáneo de la sociedad, en contraposición al constructivismo, que abogaba por un diseño consciente de instituciones, alejado de la espontaneidad. El autor considera que en el lenguaje contemporáneo no contamos con categorías precisas para este tipo de fenómenos, por 
eso prefiere recurrir a los antiguos griegos para recuperar dos nociones, cosmos y taxis, la primera hace referencia al orden espontáneo y la segunda al diseño consciente de los individuos.

En este sentido, los taxis indican una actividad que, según Hayek, no es libre, ya que implica coerción: presupone un fin determinado y los hombres involucrados en tal organización deben seguirla. No obstante, el autor se opone concretamente al relativismo moral a partir de la idea de nomos.

Una regla universal de conducta justa aplicándolo a un número desconocido de futuros ejemplos e igualmente a todas las personas en situaciones objetivas descriptas por la regla, con independencia de los efectos que la observancia de la regla producirá en una situación determinada [...]. Por contraste, usaremos tesis para significar cualquier regla aplicable solamente a personas particulares o al servicio de los objetivos de los gobernantes (1981: 68).

Al existir una norma general, se evitan los arbitrios de alguna autoridad. En todo caso, la relación entre gobiernos y ciudadanos está determinada según el grado de cumplimiento que se posea de las bases que garanticen el orden espontáneo. El argumento de Hayek es que el derecho privado, contrario al público, garantiza la libertad 
de los ciudadanos, tomando los casos de la Roma antigua y la moderna Gran Bretaña, donde el derecho era consuetudinario y no escrito, es decir, estaba en manos de jueces y juristas y no de legisladores. Estos últimos representarían al constructivismo. El correlato de esto es una crítica al Estado de Bienestar, en el que la organización, o taxis, habría reemplazado al cosmos.

El teórico y epistemólogo británico John Gray, examinó la obra de Friedrich Von Hayek (1998) desapasionadamente, mostrando los basamentos intelectuales del pensador austríaco. Al leer su trabajo sobre Hayek, se puede concluir que es erróneo considerarlo como meramente un economista, ya que la amplitud de tópicos que abarca en su obra recorre la psicología, el derecho, la filosofía, ciencias políticas, entre otras disciplinas; pero, el rasgo característico es la filosofía de la ciencia como denominador común para estas actividades.

La influencia de Kant puede observarse en varios aspectos analizando la obra de Hayek, pero los puntos principales se manifiestan en su repudio hacia el empirismo, ya que considera que los datos no nos son dados, sino que son construidos por la mente humana; por otra parte, considera que el orden social provee de la creación individual, antes que alguna necesidad natural (Gray, 1998: 20). Esto es clave para comprender cómo la noción de libertad se manifiesta: es excesivamente idealista $y$, en términos de Mario Bunge, mentalista (Bunge, 1980). Si bien el pensamiento de Hayek no es dualista — considerando una 
división mente/cuerpo-, el orden espontáneo al que hace referencia se basa en la mente y sus representaciones: el ser humano crea una serie de tradiciones, a las cuales se adapta mentalmente $y$, progresivamente, las percibe como impersonales. Hayek, al ser metodológicamente individualista, no menciona a la sociedad, pero sí una serie de representaciones, evidenciadas en la tradición de una comunidad, que se le imponen al individuo. Esto es, por lo menos, contradictorio.

Hayek, sin embargo, no estaba solo, ya que desde 1947 contaba con el apoyo del grupo que había formado, la Mont Pelerin Society, que en su primera reunión contó con economistas, historiadores y periodistas que buscaban, con sus matices, que el liberalismo clásico vuelva al centro de la escena, en pleno auge del Estado de Bienestar (Guillén Romo, 2018). En esta nueva sociedad se contaban Karl Popper y Milton Friedman.

Curiosamente, Hayek establece que el orden espontáneo, la cataláctica, sólo puede concebirse bajo la acción de emprendedores (Gray, 1980: 36) y cualquier acción estatal estorbaría en este orden. Sucede que los argumentos para apoyar este tipo de organización se basan en las fallas de los llamados socialismos reales, una herencia de uno de sus mentores, Ludwig Von Mises ${ }^{8}$. Pero esta es una construcción ideal de Hayek, como si el mundo se

8 Ver Mises, L. V. (1961). El socialismo: análisis económico y sociológico (No. 335/M67gE). 
dividiera entre órdenes espontáneos capitalistas y planeamiento central soviético. Lo mismo puede decirse de sus premisas sobre el orden legal, establecido para asegurar la creatividad de los individuos, la cual se reduciría, parcialmente, ante una Constitución. Los límites de esta coerción son inciertos. Tal abstracción fue resumida elocuentemente por Mario Bunge (1998):

Supongo que la indiferencia de Hayek por los problemas sociales se debía a que vivía en su biblioteca y solo leía libros y artículos de colegas, nunca las estadísticas ni, menos aún, la crónica diaria de la pobreza. Nunca estuvo al frente de una empresa que no fuese académica (1998: 75).

Los problemas con la lógica de Hayek son varios, y considerablemente graves. El mero hecho de considerar a la libertad como "ausencia de coerción», y que su condición de posibilidad sea brindar algo de esa libertad a una Constitución, no tiene validez empírica. Más aún, no existe caso alguno de desarrollo económico en el que el Estado no haya jugado un papel central, ya sea en Estados Unidos y en la necesidad de créditos a la agricultura en etapas críticas de su desarrollo (Stiglitz, 2010). En el proceso de formación del Estado argentino también existió una alianza entre los sectores público y privado (Oszlak, 1999). La lista de ejemplos se tornaría redundante. 
Respecto a la educación, el Estado no debería entrometerse ya que implicaría otra forma de coerción y un ataque a la libertad, en consecuencia, Hayek aboga por un sistema de vouchers a los consumidores, es decir, a las familias. Tal experimento puede verse en Chile como un auténtico fracaso: la competencia entre las escuelas privadas y públicas lleva a que los establecimientos orienten sus inversiones a mejorar su infraestructura y no necesariamente la calidad del servicio que prestan, ya que el subsidio prepondera más la tasa de asistencia en relación con la matrícula que el desempeño académico (Cox, 2003). De esta manera, sólo el segmento de la sociedad que mayores ingresos dispone puede acceder a establecimientos con ambas características (Hsieh \& Urquiola, 2006).

Finalmente, Hayek no considera a los actores reales de la economía (Sufrin, 1961), como sindicatos o grupos de presión, en consecuencia, su concepción de libertad es metafísica y no puede verificarse empíricamente.

\section{Milton Friedman: ¿libre para elegir?}

Milton Friedman es uno de los economistas fundamentales para comprender la historia de la disciplina, pero, en simultáneo, comprenderlo implica entender cómo se desarrolló, en gran medida, la segunda mitad del siglo XX. Si bien Friedman empezó su actividad profesional en los 
años 30 y siempre mantuvo una postura neoclásica, es conocido por llevar al pensamiento neoclásico nuevamente al mainstream entre los años 70 y 80 , lo que la convirtió en la nueva hegemonía económica. Los aportes de Friedman sobre la racionalidad de los individuos, el refinamiento de la teoría cuantitativa del dinero, y la relación entre inflación y desempleo, no son discutidos en este espacio; sólo se abordará su concepción sobre la libertad.

El carácter semántico de libertad en Friedman suele ser muy vago $y$, generalmente, relacionado con alguna intención política coyuntural. Tuvo un libro titulado Free to choose (1980) — Libre para elegir (1983) — , un programa con emisión en habla hispana-y un think tank con ese mismo nombre; por otra parte, free o freedom aparecen en varias de sus conferencias, que sirvieron como divulgación de las ideas neoclásicas en pleno gobierno de Ronald Reagan. Dentro de su obra, la noción de libertad no abandona su vaguedad.

Friedman comenzó su carrera como divulgador incluso antes de que existiera la sociedad Mont Pelerin, ya que en 1946 lanzó, junto a George Stigler —otro economista que sería Premio Nobel-, el trabajo Roofs or Ceilings? The Current Housing Problem, un panfleto difundido por una organización libertaria, la Foundation of Economic Education (Krugman, 2007). Sin mucho éxito pululó por algunos programas de televisión criticando al Estado de Bienestar, pero la fortuna cambiaría cuando sus aportes 
académicos comenzaron a ser reconocidos $y$, finalmente, le merecieron un premio Nobel en 1976 (Krugman, 2007).

El libro de divulgación Capitalismo y libertad (2002) tuvo un considerable impacto en el público general, para el que el camino ya estaba allanado en parte con trabajos divulgativos como los de Hayek, ya mencionados en este artículo. Se trataba del conservadurismo que ataca al Estado de Bienestar. La tesis principal del libro de Milton Friedman es que el capitalismo de libre mercado es una condición esencial para la libertad política, ya que en el intercambio de bienes siempre existiría una acción voluntaria, no coercitiva, algo que es propiedad del Estado. Sin embargo, lo que Friedman pretende señalar como libertad parece guardar relación con que el individuo «sea responsable de su propio destino» (2002: 1), o más bien, leyes que resguarden «libertades civiles» (2002: 5) o la no agresión entre los ciudadanos (2002: 26).

Milton Friedman se refiere en reiteradas ocasiones al «hombre libre» - free man-, pero no aclara a qué se refiere con esto. En cambio, se entiende que la libertad se pierde con la intervención gubernamental, la cual sólo debe enfocarse en «proteger la libertad de los enemigos internos y extranjeros; preservar la ley y el orden, reforzar contratos privados y proteger los contratos privados» (2002: 4). Dado que libertad no es operacionalizado, se puede entender, indirectamente, por el legado filosófico que Friedman retoma: Dicey, Mises, Hayek y Simons (2002: 11), entre otros. Precisamente, el pensamiento de Friedrich Von Hayek 
en torno a la libertad fue abordado, en consecuencia, puede rastrearse cierta conexión respecto a concebir a la libertad como ausencia de coerción estatal o civil basándose en los postulados de una Constitución, a las que el autor se refiere como «reglas de juego» (2002: 25). Explícitamente, Friedman se refiere a la libertad, de manera relacional, como ausencia de coerción: «la libertad política implica la ausencia de coerción de los demás ciudadanos» (2002: 15).

Milton Friedman vuelve a referirse al rol del Estado, pero nuevamente lo hace de manera relacional en un apartado llamado El papel del Estado en una sociedad libre, en el que se afirma que el aparato estatal debe «proveer los medios necesarios para modificar las reglas, se garantiza la discusión ciudadana de esas normas, y facilitar el acatamiento por parte de quienes, de una manera u otra, no participan de ese debate» (2002: 25).

El problema surge en que el concepto nunca se operacionaliza, sino que se lo relaciona con un mercado donde el Estado no intervenga, los agentes se guíen por las señales de precios o, en todo caso, el vocablo libertad se relaciona con adjetivos como libertad política o libertad económica, pero no se aclara a qué se está refiriendo en cada caso.

Milton Friedman establece que la libertad es el fin último al que una sociedad debe aspirar, y el Estado, o el pensamiento colectivista — socialismo, comunismo o Estado de Bienestar - serían los obstáculos para que esto se realice. De esta manera, si bien el autor no contempla que 
los autores sean racionales, ya que deben existir acuerdos legales mínimos para la coexistencia entre los individuos, estos se guían por el mercado y la libre empresa, es decir, el egoísmo. En este sentido, el concepto de libertad en Friedman parece estar cargado de economicismo, por ejemplo, al situar los casos de los niños y los insanos en términos de que no sería beneficioso para el individuo que estos elijan por su propia cuenta (2002: 33). Esto justificaría la intervención estatal en el caso de quienes se vean psicológicamente inhabilitados para tomar decisiones, mientras que los niños serían «potenciales consumidores», con libertades para sí mismos y no meras extensiones de sus padres (2002: 33).

Si se toma el modelo de Friedman, en el que los individuos se guían por las señales de precio para ejercer una libertad voluntarista y se amparan en la ley para evitar conflictos entre sí, y se sigue a Ashford (2010), luego de arduas jornadas laborales, con su respectivo descanso, ¿qué hace pensar que el ciudadano puede ejercer plenamente su ciudadanía? Un mínimo ejemplo, el del votante promedio, que no tiene suficiente información y sus ingresos no le permiten tener el tiempo suficiente para evaluar alternativas políticas (Bishop, 1991), es lo necesariamente ilustrativo para ver lo ilusorio de la propuesta de Friedman.

Por otra parte, el modelo de Milton Friedman es demasiado ingenuo al no considerar fallas de mercado: no aborda la concentración de la riqueza, la desigualdad distributiva o la explotación. Parecería que no existiría 
coerción alguna en el sector privado. Esto queda reflejado en cómo el economista considera al empresario: como un agente que debe maximizar su ganancia, de hecho, ese es su deber social (Friedman, 1970). Se supone que para Friedman la libertad económica y política son fines en sí mismos, de ahí la relación entre capitalismo y libertad (Vorster, 2010), pero la libertad de elección en un libre mercado, propuesta por el intelectual neoyorquino, se caracteriza por su pobreza teórica.

En otro libro de divulgación, Libre para elegir (1983), Friedman recopila lo que luego serían los episodios de la serie homónima. Es notable cómo en el comienzo del texto, precisamente en el capítulo «El poder del mercado», éste aparece como neutral, sin valores 0 , en rigor, con el egoísmo o el interés propio como meta. Quizá el mejor ejemplo sobre esta concepción lo da cómo presenta el cuento Yo, el lápiz.

Nadie que ocupase una oficina central dio órdenes a esos millares de personas. Ninguna policía militar hizo cumplir unas órdenes, porque no fueron dadas. Quienes intervinieron en el proceso viven en varios países, hablan distintas lenguas, practican religiones diferentes, pueden, incluso, odiarse entre sí, pero ni siquiera estas diferencias impidieron su cooperación para fabricar un lápiz. ¿Cómo llegó, entonces, a producirse? Adam Smith nos dio la respuesta hace doscientos años (Friedman, 1983:27). 
La respuesta sería «la mano invisible», pero, incluso suponiendo que ninguna policía militar hizo cumplir órdenes -en clara alusión al régimen soviético一, ¿no existe explotación, condiciones de vida paupérrimas que obligan a los individuos a trabajar o, simplemente, el hecho de tener un trabajo para que se reproduzca la vida social? Al igual que Hayek, Friedman parece olvidar que existen hechos sociales. No obstante, el economista deja en claro dónde el mercado no puede aparecer y, en consecuencia, el Estado tomaría un rol protagónico:

A government which maintained law and order, defined property rights, served as a means whereby we could modify property rights and other rules of the economic game, adjudicated disputes about the interpretation of the rules, enforced contracts, promoted competition, provided a monetary framework, engaged in activities to counter technical monopolies and to overcome neighborhood effects widely regarded as sufficiently important to justify government intervention, and which supplemented private charity and the private family in protecting the irresponsible, whether madman or child — such a government would clearly have important functions to perform. The consistent liberal is not an anarchist (en Macpherson, 1968: 34).

La propuesta es demasiado abstracta, y sólo se puede verificar empíricamente en The role of monetary policy 
(1968) —en relación a un marco de política monetaria-; por otra parte, no se define qué actividades evitarían la concentración monopólica y, conformando un absurdo, se supone que el Estado debería fomentar la iniciativa privada para proteger a los enfermos psiquiátricos. La teoría política de Milton Friedman se asemeja al laissez-faire del siglo XIX, y de aplicarse, sóo llevaría a la explotación, concentración de la riqueza, desigualdad de ingresos, desprotección de enfermos, huérfanos, y apertura de mercados con pocas barreras a la entrada. Esto no implica igualdad de condiciones en el mercado, no existe ningún tipo de libertad de elección si, por ejemplo, existen asimetrías de información.

Al analizar los trabajos de Milton Friedman en los que desarrolla su teoría política, podemos concluir que el concepto de libertad, en sí, no es operacionalizado; se infiere que su referencia es la libertad del individuo para realizar alguna acción que no infrinja las leyes establecidas en determinada comunidad y que el Estado no se le interponga. En todo caso, el concepto se relaciona, en gran medida, con libertades políticas - vagamente definidas- y libertad económica, entendiendo por esto la menor interferencia posible de la burocracia estatal en el ámbito económico. 
Tras haber analizado una selección de trabajos de Karl Popper, Friedrich Von Hayek y Milton Friedman, es posible arribar a una serie de conclusiones respecto a cómo estos autores emplean el término libertad. En Popper encontramos una fuerte relación entre el concepto de libertad, el método hipotético-deductivo y lo que él denomina sociedades abiertas. Mediante un procedimiento de conjeturas y refutaciones, los individuos podrían garantizar un orden social que pueda ser superado, donde las verdades no están dadas, sino sujetas a interrogación. Lo contrario ocurre, para el epistemólogo, en sistemas totalitarios, guiados por el historicismo y su concepción teleológica de la historia.

Al analizar el caso de Friedrich Von Hayek, hallamos similitudes con Popper respecto a la concepción de sociedades abiertas como condición necesaria para el desarrollo de un sistema social, sin embargo, el intelectual austríaco relaciona a la libertad con la ausencia de coerción, la cual, en términos generales, proviene de la burocracia estatal, ya que se compondría de agentes que crean instituciones artificiales, las cuales devienen en un impedimento para la clave por la cual se reproduce la vida social según Hayek: el descubrimiento y la creatividad en un mercado libre, mediante el sistema de precios, la cataláctica. En última instancia, la única coerción que Hayek admite como legítima es la de una Constitución que permita el desarrollo armónico de un proceso de mercado. 
Si bien los dos primeros autores distinguen claramente sus conceptos de libertad, Milton Friedman no lo hace, y más bien se infiere que el lector ya sabe a lo que se está refiriendo. De cualquier manera, el contenido del vocablo libertad, en este caso, suele relacionarse con libertad política y económica, aunque estos terrenos tampoco son operacionalizados, más allá de alguna mención a la validez de las leyes y su discusión. En rigor, Friedman parece abogar por una libertad de mercado donde el Estado solo se involucre para garantizar que las transacciones puedan llevarse a cabo sin que se incurra en violencia entre los agentes involucrados. Es en estos términos donde se puede concebir a una sociedad como libre, es decir, mínima intervención del Estado y un sistema de libre empresa.

Encontramos que los tres autores abogan por sociedades abiertas, libertad de comercio y poca intervención estatal en la vida cívica, a no ser por un marco institucional que permita que los individuos puedan desarrollarse. No obstante, el sentido que se le otorga al concepto de libertad parece cobrar una veta política considerando que los intelectuales en cuestión compartían la agenda de la sociedad Mont Pelerin, se oponían a lo que denominaron colectivismos en pleno contexto de Guerra Fría y auge del Estado de Bienestar. Considerando la influencia que han tenido en regímenes que dieron paso a la hegemonía neoliberal, como los de Ronald Reagan y Margaret Thatcher, los usos de libertad en estos autores se 
relacionan con procesos políticos más que meras disputas filosóficas.

\section{Bibliografía}

Alonso, L. E. \& Conde, F. (1996). Las paradojas de la globalización: la crisis del estado del bienestar nacional y las regiones vulnerables. Revista de Estudios regionales 44, 87-124.

Arana, J. (2001). Determinismo y libertad en Karl Popper. Anuario filosófico 34 (1), 119-138.

Ashford, R. (2010). Milton Friedman's capitalism and freedom: A binary economic critique. Journal of Economic Issues 44 (2), 533-542.

Bishop, J. A., Formby, J. P., \& Smith, W. J. (1991). Incomplete information, income redistribution and risk averse median voter behavior. Public Choice 68 (1-3), 41-55.

Boettke, P. J. (1995). Hayek's The Road to Serfdom revisited: Government failure in the argument against socialism. Eastern Economic Journal 21 (1), 7-26.

Buchanan, J. M. (2003). What is public choice theory? Rationalizing capitalist democracy: The cold war origins of rational choice liberalism, 133.

Bunge, M. (1980). El problema mente-cuerpo. 
Bunge, M. (1998). Elogio de la curiosidad. Editorial Sudamericana.

Caro, C. O. (2007). Sobre la incompatibilidad indeterminismo-libertad en el racionalismo crítico de Karl Popper. Revista de Ciencias Sociales (CI), (18), 1933.

Castel, R. (2010). El ascenso de las incertidumbres. Trabajo, protecciones, estatuto del individuo, Buenos Aires: Fondo de Cultura Económica.

Cordero, A. (2007). Mercado y bienestar colectivo en La fatal arrogancia de Federico Hayek. Revista Venezolana de Economía y Ciencias Sociales 13 (1), 63-84.

Cox, C. (2003). Las políticas educacionales de Chile en las últimas dos décadas del siglo XX. Políticas educacionales en el cambio de siglo. La reforma del sistema escolar en Chile, 19-113.

Friedman, M., \& Stigler, G. J. (1946). Roofs or Ceilings?: The Current Housing Problem. National Association of Real Estate Boards.

Friedman, M. (1968). The role of monetary policy. American Economic Review.

Friedman, M. (1970). La responsabilidad social de la empresa es incrementar sus beneficios. The New York Times Magazine, 13.

Friedman, M., Friedman, R., \& Lladó, A. (1983). Libertad de elegir. Madrid: Orbis.

Friedman, M. (2002). Capitalism and freedom. University of Chicago Press. 
Gómez Betancourt, R. (2008). La teoría del ciclo económico de Friedrich von Hayek: causas monetarias, efectos reales. Cuadernos de Economía 27 (48), 47-69.

Gray, John. (1998). Hayek on Liberty. Routledge 3rd edition. Guillén Romo, H. (2018). Los orígenes del neoliberalismo: del Coloquio Lippmann a la Sociedad del MontPèlerin. Economía UNAM 15 (43), 7-42.

Hacohen, M. H. (1998). Karl Popper, the Vienna circle, and red Vienna. Journal of the History of Ideas 59 (4), 711734.

Hacohen, M. H. (1999). Dilemmas of cosmopolitanism: Karl Popper, Jewish identity, and «central European culture». The Journal of Modern History 71 (1), 105149.

Hacohen, M., \& Milford, K. (2002). Karl Popper: The Formative Years, 1902-1945; Politics and Philosophy in Interwar Vienna. In History of Philosophy of Science (pp. 399-404). Springer, Dordrecht.

Hayek, F. A. (1946). Individualism: true and false. Hodges, Figgis \& Company.

Hayek, F. A. (1978). Camino de servidumbre. Primera edición en libro de bolsillo. Madrid: Alianza Editorial.

Hayek, F. (1981). Nuevos estudios en filosofía, política, economía e historia de las ideas. Eudeba.

Hayek, F. A. (1998). Los fundamentos de la libertad (Vol. 5). Unión Editorial.

Hsieh, C. T., \& Urquiola, M. (2006). The effects of generalized school choice on achievement and stratification: 
Evidence from Chile's voucher program. Journal of public Economics 90 (8-9), 1477-1503.

Jürgensen, K., \& Rosende, F. Hayek y el Ciclo Económico:

Una Revisión a la Luz de la Macroeconomía Moderna (No. 154). Instituto de Economía. Pontificia Universidad Católica de Chile.

Krugman, P. (2007). Who Was Milton Friedman? New York Review of Books 54 (2), 27.

Lagoa, J. E. F. (2002). Popper: La sociedad abierta como requisito de la libertad. Cuadernos de estrategia (115), 115-139.

Macpherson, C. B. (1968). Elegant tombstones: a note on Friedman's freedom. Canadian Journal of Political Science/Revue canadienne de science politique 1 (1), 95-106.

Oszlak, O. (1999). La formación del estado argentino: orden, progreso y organización nacional. Editorial Planeta.

Petersen, K. (2013). The early Cold War and the Western welfare state. Journal of International and Comparative Social Policy 29 (3), 226-240.

Plehwe, D., Walpen, B. J., \& Neunhöffer, G. (Eds.). (2007). Neoliberal hegemony: $A$ global critique. Routledge.

Popper, K. R. (2002). Búsqueda sin término. Una autobiografía intelectual. Madrid: Alianza Editorial.

Popper, K. (2002). La miseria del historicismo, trad. de Pedro Schwartz. Madrid: Alianza Editorial. 
Popper, K. R. (2004). La lógica de la investigación científica. Tecnos.

Popper, K. (2006). La sociedad abierta y sus enemigos (trad. Eduardo Loedel).

Rosenof, T. (1974). Freedom, Planning, and Totalitarianism:

The Reception of FA Hayek's Road to

Serfdom. Canadian Review of American Studies 5 (2), 149-165.

Shearmur, J. (2006). Hayek, The Road to Serfdom, and the British Conservatives. Journal of the History of Economic Thought 28 (3), 309-314.

Skinner, Q. (2012). Liberty before liberalism. Cambridge University Press.

Sufrin, S. C. (1961). Some Reflections on Hayek's The Constitution of Liberty. Ethics 71 (3), 201-204.

Stiglitz, J. E. (2010). El malestar en la globalización. Taurus.

Von Hayek, F. A. (1937). Economics and knowledge. Economica 4 (13), 33-54.

Von Hayek, F. A. (1982). Los principios de un orden social liberal. Estudios públicos (6).

Von Hayek, F. (2010). La fatal arrogancia. Los errores del socialismo. Unión Editorial. 